\section{Barite Recrystallization to Witherite in the Presence of Carbonate, and the Impact on Radium Retention}

MOHAMMED ALZAYDAN ${ }^{1,2}$, THOMAS ROTH ${ }^{2}$, FRANK HEBERLING $^{2}$, ROBERT POLLY ${ }^{2}$, DIETER SCHILD ${ }^{2}$ AND VOLKER METZ ${ }^{2}$

${ }^{1}$ King Abdulaziz City for Science and Technology (KACST)

${ }^{2}$ Karlsruhe Institute of Technology (KIT)

Presenting Author: mohammed.alzaydan@kit.edu

For geological disposal of nuclear waste the (geo-)technical barrier system supports protection against groundwater contact. Since intrusion of solutions into disposal rooms has to be considered on a long term, chemical reactions between the waste forms and intruding solutions must be taken into account within the safety case of a repository. As sulfate containing groundwater contacts the waste, barite $\left(\mathrm{BaSO}_{4}\right)$ formation is expected. Radium ( $\mathrm{Ra}$ ) uptake by barite occurs when dissolved Ra reacts with barite, leading to $\mathrm{Ra}$ retention in a $(\mathrm{Ba}, \mathrm{Ra}) \mathrm{SO}_{4}$ solidsolution [1]. On the other side, barite reaction with aqueous carbonate at high $\mathrm{pH}$, e.g. due to the alteration of cementitious material inside a repository, may cause barite to convert into witherite $\left(\mathrm{BaCO}_{3}\right)$ [2]. Carbonate presence likely alters the chemical behaviour of barite surfaces, via surface mixing or by witherite layer formation through dissolution-precipitation [3]. Aim of this study is to investigate the effect of carbonate on $\mathrm{Ra}$ retention by barite / witherite. The presented results highlight barite transformation into witherite in the absence of Ra.

Batches of barite were contacted with carbonate solutions (1$100 \mathrm{mM}, \mathrm{pH}$ 7-11). X-ray diffraction (XRD) showed shifts of reflection peaks in batches with $\mathrm{pH}$ values of 9-11 and carbonate concentrations of 10-100 mM, indicating a witherite-barite solidsolution formation [3]. Reaction rates depend on the type of barite used. In general, reactions slow down after about 7 days, likely due to surface passivation. Cubes cut from natural barite, were reacted with $100 \mathrm{mM}$ carbonate solutions at $\mathrm{pH} 11$. As a result, a porous witherite layer with $(271 \pm 32) \mu \mathrm{m}$ formed giving insight into recrystallization process progress and mechanism.

We acknowledge KACST funding and the German federal ministry for education and research for funding the travel through the collaborative project KRIMI, grant agreement 02NUK056A.

[1] Heberling et al. (2018) Geochim. Cosmochim. Acta 232, 124-139.

[2] Rendón-Angeles et al. (2008) J. Materials Science 43, 2189-2197.

[3] Putnis and Putnis (2007) J. Solid State Chemistry 180, 1783-1786.

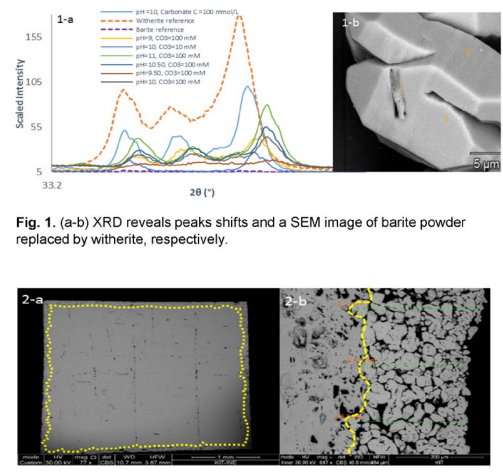

Fig. 2. (a-b) Witherite layer and its thickness for 15 day reaction period cube, 